\title{
Analysis of genetic diversity of muga silkworm (Antheraea assamensis, Helfer; Lepidoptera : Saturniidae) using RAPD-based molecular markers
}

\author{
Kartik Neog ${ }^{1}$, H. Ranjit Singh ${ }^{2}$, Balagopalan Unni ${ }^{2 *}$ and A. K. Sahu ${ }^{3}$ \\ ${ }^{1}$ Central Muga Eri Research and Training Institute (CMER\&TI), Central Silk Board, Lahdoigarh, Jorhat 785 700, Assam, \\ India. \\ ${ }^{2}$ Biotechnology Division, North East Institute of Science and Technology (NEIST), Jorhat 785 006, India. \\ ${ }^{3}$ Regional Muga Research Station (RMRS), Central Silk Board, Boko, Kamrup, Assam, India.
}

Accepted 16 February, 2010

\begin{abstract}
Eleven populations of muga silkworm, Antheraea assamensis Helfer, the golden silk yarn producer of northeast India, was subjected to RAPD marker analysis in order to assess its genetic diversity. The genomic DNA extracted from muga silkworms were analysed using 50 random primers among which 36 polymorphic primers generated 309 bands. RAPD profile of the isolated DNA revealed a high level of genetic polymorphism. The average amplicons per primer was found to be 8.58 , and $94.82 \%$ amplicons were polymorphic. Cluster analysis based on Jaccard's similarity coefficients resulted in the formation of two main clusters with one population on one cluster and the remaining on the other cluster. Jaccard's similarity coefficients ranged from 0.122 to 0.863 indicating a high level of genetic diversity within muga silkworm collection. The study concluded that, although there lays little morphological differences among the collected muga silkworm populations, the populations are highly polymorphic which might have enabled the silkworm to survive under a restricted geographical location, that is north east region of India only but under diverse climatic conditions for a long period. This study may be useful in identifying diverse genetic stocks of $A$. assamensis, which may be conserved on a priority basis.
\end{abstract}

Key words: Muga silkworm, Antheraea assamensis, RAPD markers, genetic diversity.

\section{INTRODUCTION}

Silkworm is a domesticated insect having been cultured for a period of over 5000 years (Goldsmith, 1995). It possesses excellent characteristics as an experimental organism. There are numerous characters in all stages of silkworm that are heritable. The morphological characters like body colour, shell weight, cocoon weight, etc. has been traditionally used to identify a strain. Lack of assessing genetic diversity in the available germplasm, unavailability of modern tools to know the genomes at molecular level, environmental disturbances during the time of selection and phylogenetic control of various traits

*Corresponding author. E-mail: bgunni@rrljorhat.res.in. Fax: 0376-2370011 / 2370315. in silkworm have led to the poor selection of parents in breeding programs (Datta, 1984; Williams et al., 1990; Singh, 1997; Ashwath, 2000; Vijaya et al., 2006). It is well known that the resistance to biotic and abiotic constraints is governed by polygenes with complex inheritance patterns and with lot of environmental influences (Promboon et al., 1995). Therefore it is required to produce genotypes for a particular geographical environment by utilizing the races acclimatized to that location. New tools like molecular markers can be effectively applied with conventional breeding strategies and the genes for the resistance can be discovered (Murthy et al., 2006).

Muga silk is a wonderful gift of nature extracted from an insect species called Antheraea assamensis Helfer. Rearing of Muga silkworm is done and restricted only to the north eastern region (NER) of India. Considering the 
Table 1. Origin and quantitative traits of 11 muga silkworm accessions studied.

\begin{tabular}{|l|l|l|l|c|c|c|c|}
\hline Accession No. & \multicolumn{1}{|c|}{ Origin } & Larval colour & $\begin{array}{c}\text { Larval } \\
\text { weight } \\
\mathbf{( g )}\end{array}$ & $\begin{array}{c}\text { Cocoon } \\
\text { weight (g) }\end{array}$ & $\begin{array}{c}\text { Pupal } \\
\text { weight } \\
\text { (g) }\end{array}$ & $\begin{array}{c}\text { Shell } \\
\text { weight } \\
\text { (g) }\end{array}$ & SR (\%) \\
\hline Aa 01 & Mangaldoi, Assam & Green & 9.457 & 3.827 & 3.535 & 0.247 & 6.45 \\
Aa 02 & Tura, Meghalaya & Green & 9.820 & 4.346 & 4.042 & 0.259 & 5.96 \\
Aa 03 & Jorhat, Assam & Green & 10.442 & 3.835 & 3.540 & 0.253 & 6.69 \\
Aa 04 & Tura, Meghalaya & Deep green & 10.638 & 3.974 & 3.687 & 0.250 & 6.29 \\
Aa 05 & Tura, Meghalaya & Deep green & 12.337 & 4.098 & 3.819 & 0.233 & 5.68 \\
Aa 06 & Tura, Meghalaya & Deep green & 14.035 & 3.501 & 3.228 & 0.234 & 6.68 \\
Aa 07 & Tura, Meghalaya & Deep green & 12.335 & 4.381 & 4.049 & 0.288 & 6.57 \\
Aa 08 & Lahing, Assam & Blue & 14.429 & 5.107 & 4.722 & 0.331 & 6.48 \\
Aa 09 & Mokokchung, Nagaland & Green & 9.332 & 4.190 & 3.895 & 0.252 & 6.01 \\
Aa 10 & Mokokchung, Nagaland & Green & 11.238 & 4.032 & 3.725 & 0.265 & 6.57 \\
Aa 11 & Baghmara, Meghalaya & Green & 11.241 & 4.033 & 3.737 & 0.255 & 6.32 \\
\hline
\end{tabular}

ecological conditions, food plant distribution, presence of eco-types and species of diverse nature in co-existence, it is speculated that this region is a possible home of origin of Antheraea, from where radiations would have occurred. This species has the lowest number of chromosome $(n=15)$ compared to other species of Antheraea and also considered to be endangered in near future.

For breeding or improving promising cultivars of a plant or race of a silkworm, precise determination and discrimination of the genotypes are required. The most desirable or suitable silkworm race with disease tolerance or high yielding characteristics can be developed using molecular markers in selection and breeding. Random amplified polymorphic DNA (RAPD) markers developed during the last two decades have been successfully and largely utilized for taxonomic and systematic classification as well as phylogenic or genetic diversity studies of plants (Rath et al., 1998; Sun et al., 2005; Adiguzel et al., 2006; Meimberg et al., 2006; Hug and Roger, 2007) and in insects like corn borer (Pornkulwat et al., 1998; Krumm et al., 2008), gypsy moth, Lymantia dispar (Reineke et al., 1999) and silkworms (Nagaraja and Nagaraju, 1995; Promboon et al., 1995; Thanananta et al., 1997; Awasthi et al., 2008; Ribeiro et al., 2009).

Earlier classification and evaluation of $A$. assamensis were based mostly on morphological characteristics and rearing performance over a given period of time (Choudhury, 2005; Chakravorty et al., 2006; Neog et al., 2008). But till now, a definite race of the silkworm is not available with distinct morphological, anatomical or rearing behaviour. Survey on literature failed to uncover any published record on molecular characterization of $A$. assamensis based on molecular markers. Hence, attempts were made for the first time to characterize the muga silkworm accessions/genotypes using RAPD markers collected from different localities of the northeastern region of India.

\section{MATERIALS AND METHODS}

\section{Silkworm collection}

Survey was conducted in the NER of India to collect cultivated and wild muga silkworm stocks. Maximum care was taken to avoid duplication of the collected germplasm particularly in respect of origin of seed source of the cultivated stocks. A total of eleven populations, comprising four from cultivated and seven from wild stock having divergent geographical origin were collected and utilized in the present study. Each population was given accession numbers from Aa 01 to $\mathrm{Aa} 11$ (Table 1 and Figure 1). Accession numbers $\mathrm{Aa} 04$ to $\mathrm{Aa} 07$ were collected by Regional Muga Research Station (RMRS), Central Silk Board, Boko, Assam, India and the rest by Central Muga Eri Research and Training Institute, Central Silk Board, Lahdoigarh, Jorhat, Assam, India. All the accessions are being maintained at CMER\&TI following recommended rearing practices (Chakravorty et al., 2005).

\section{Genomic DNA isolation}

Each individual larva at fifth instar (day 3) was collected and DNA was isolated from the posterior silk gland (Suzuki et al., 1972; Thanananta et al., 1997; Nagaraja, 2002; Nagaraja and Nagaraju, 1995). About $100 \mathrm{mg}$ of the silk gland tissues were dipped in fixing solution and absolute alcohol for $30 \mathrm{~min}$. After allowing alcohol to evaporate, the tissue was ground with a mortar and pestle and the homogenized tissue was transferred to pre-warmed extraction buffer (100 mM Tris buffer, pH 8.0 containing 2.5\% SDS, $1.4 \mathrm{M}$ $\mathrm{NaCl}, 25 \mathrm{mM}$ EDTA, pH 8.0 and $0.8 \% \beta$-mercaptoethanol) in an Oakridge tube. It was incubated at $65^{\circ} \mathrm{C}$ in a water bath and occasionally mixed by gentle swirling. After one hour of incubation, it was removed from the water bath. The DNA was then extracted with chloroform-isoamyl alcohol (24:1). The extracted DNA was precipitated in ethanol in the presence of $3.0 \mathrm{M}$ sodium acetate $(\mathrm{pH}$ $5.4-5.6)$ and resuspended in TE buffer $(10 \mathrm{mM}$ Tris- $\mathrm{HCl}, 1.0 \mathrm{mM}$ EDTA, pH 8.0). The RNA contamination was removed by incubating with RNase $A(100 \mu \mathrm{g} / \mathrm{ml})$ at $37^{\circ} \mathrm{C}$ for $1 \mathrm{~h}$. The genomic DNA thus obtained was quantified on $0.8 \%$ agarose gel against a known quantity of unrestricted lambda DNA.

\section{Polymerase chain reaction (PCR) amplification}

For standardization of optimum PCR amplification, experiments 


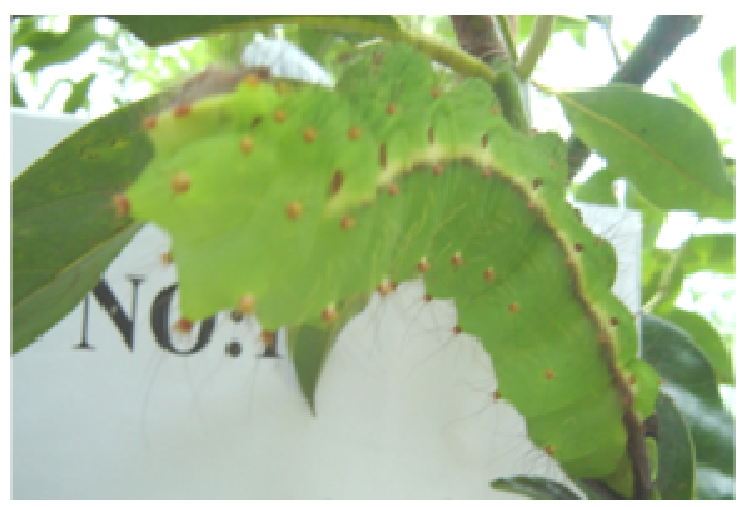

Aa 02 (Green)

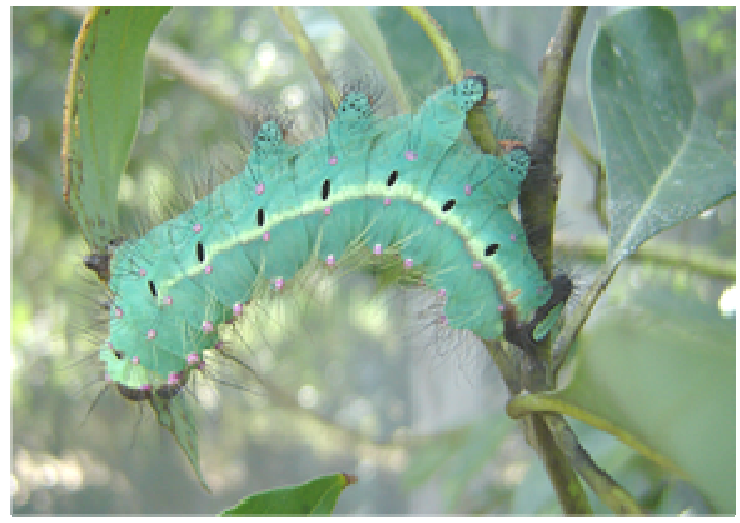

Aa 08 (Blue)

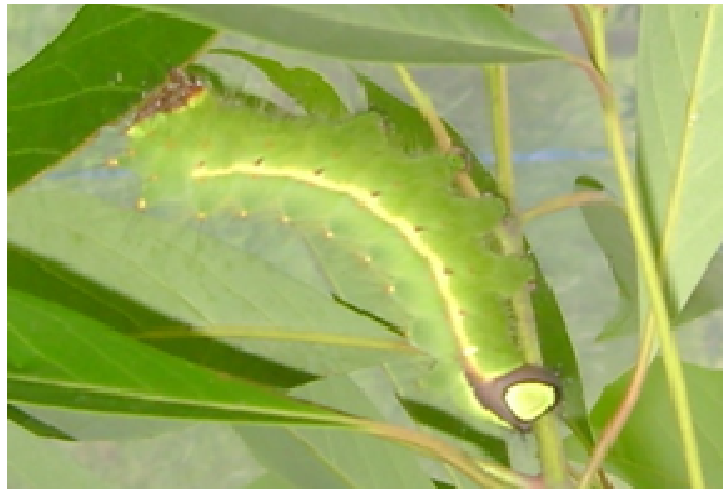

Aa 05 (Green)

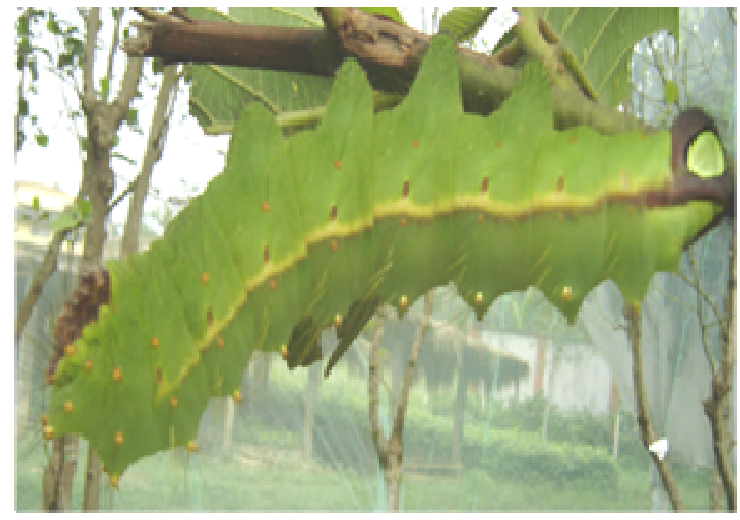

Aa 11 (Green)

Figure 1. Variation in larval colour (green and blue) of few muga silkworm accessions.

were carried out with varying concentrations of template DNA, Taq polymerase, primer, $\mathrm{MgCl}_{2}$ and deoxyribonucleotide triphosphates (dNTPs). For PCR-RAPD analysis, 36 decamer RAPD primers were used from Bangalore Genei (Bangalore, India). Amplification was performed in a thermal cycler (Applied Biosystems, Germany) with $25 \mu$ reaction mixture containing $2.5 \mu$ l buffer $(10 \times$ Taq DNA polymerase buffer containing $15 \mathrm{mM} \mathrm{MgCl}, 2.5 \mu \mathrm{M}$ dNTPs (from 10-mM stock), $20 \mathrm{pM}$ primer (random decamer primer), 1 unit of Taq DNA polymerase (all from Bangalore Genei, Bangalore, India) and $30 \mathrm{ng}$ of genomic DNA.

The amplification program was as follows: 1 cycle of $94^{\circ} \mathrm{C}$ for 4 min, 40 cycles of $94^{\circ} \mathrm{C}$ for $1 \mathrm{~min}, 37^{\circ} \mathrm{C}$ for $1 \mathrm{~min}, 72^{\circ} \mathrm{C}$ for $2 \mathrm{~min}$, followed by $72^{\circ} \mathrm{C}$ for $5 \mathrm{~min}$. Amplified PCR products were separated on agarose gel $(2 \% \mathrm{w} / \mathrm{v})$ in $1 \mathrm{X}$ TBE $(100 \mathrm{mM}$ Tris- $\mathrm{HCl}, \mathrm{pH} 8.0,83$ $\mathrm{mM}$ Boric Acid, 1mM EDTA, pH 8.0) at $70 \mathrm{~V}$ for $150 \mathrm{~min}$. The gel was visualized by staining with ethidium bromide and photographed under UV light by a Multi Doc-It Digital Imaging System (UVP Ltd., UK).

\section{Statistical analysis}

The DNA fragment amplified by a primer in each gel was analyzed by scoring the bands as present (1) or absent (0). Data matrices were entered into the NTsys version $2.02 \mathrm{~K}$ package, a pairwise comparison of germplasm accessions was made and genetic diversity parameters were calculated. Genetic similarities based on Jaccard's similarity coefficient were calculated among all possible pairs, using Simqual option and ordering in a similarity matrix. Based on the data, a dendogram was prepared by the unweighted pair group method with arithmetic mean (UPGMA) (Sokal and Sneath, 1963) and using a statistical software package "SPSS for MS Windows Release 10.0" to group the individual populations into discrete clusters.

\section{RESULTS AND DISCUSSION}

Genomic DNA was extracted from silk glands of muga silkworms by a modified method of Suzuki et al. (1972). Here, instead of grinding the tissues in liquid nitrogen, the silk gland tissues were first dipped in absolute alcohol followed by submerging in $500 \mu \mathrm{L}$ of alcohol for $30 \mathrm{~min}$. After allowing alcohol to evaporate, the tissue was ground with a mortar and pestle and the homogenized tissue was transferred to pre-warmed extraction buffer to extract DNA. Additionally, $\beta$-mercaptoethanol was also added in the extraction buffer for denaturing proteins/ enzymes. 
$\begin{array}{lllllllllllll}1 & 2 & 3 & 4 & 5 & 6 & 7 & 8 & 9 & 10 & 11 & \mathrm{M}\end{array}$
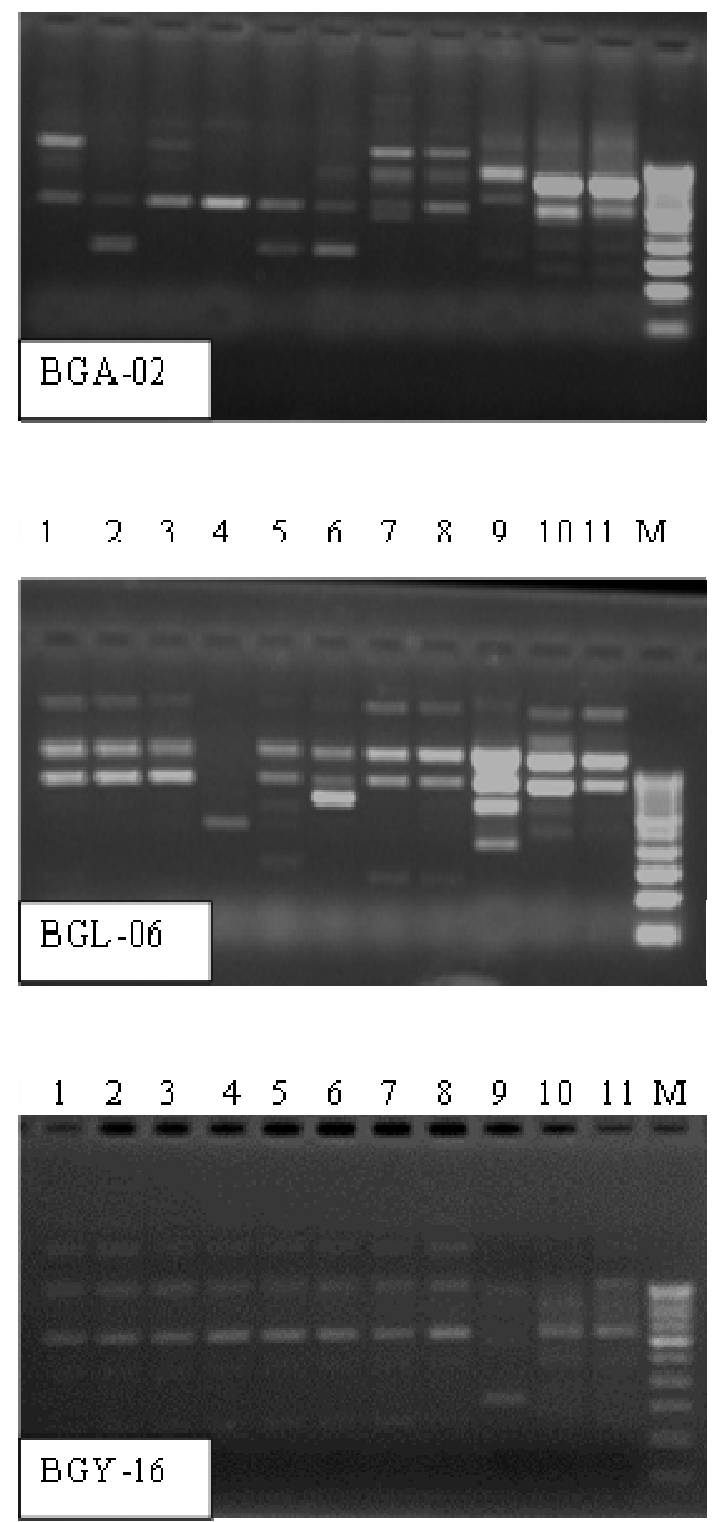

\section{$\begin{array}{lllllllllllll}1 & 2 & 3 & 4 & 5 & 6 & 7 & 8 & 9 & 10 & 11 & \mathrm{M}\end{array}$}

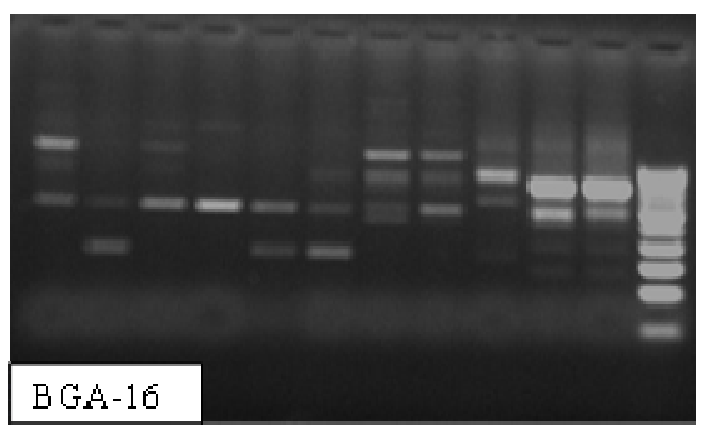

$\begin{array}{lllllllllllll}1 & 2 & 3 & 4 & 5 & 6 & 7 & 8 & 0 & 10 & 11 & \mathrm{M}\end{array}$
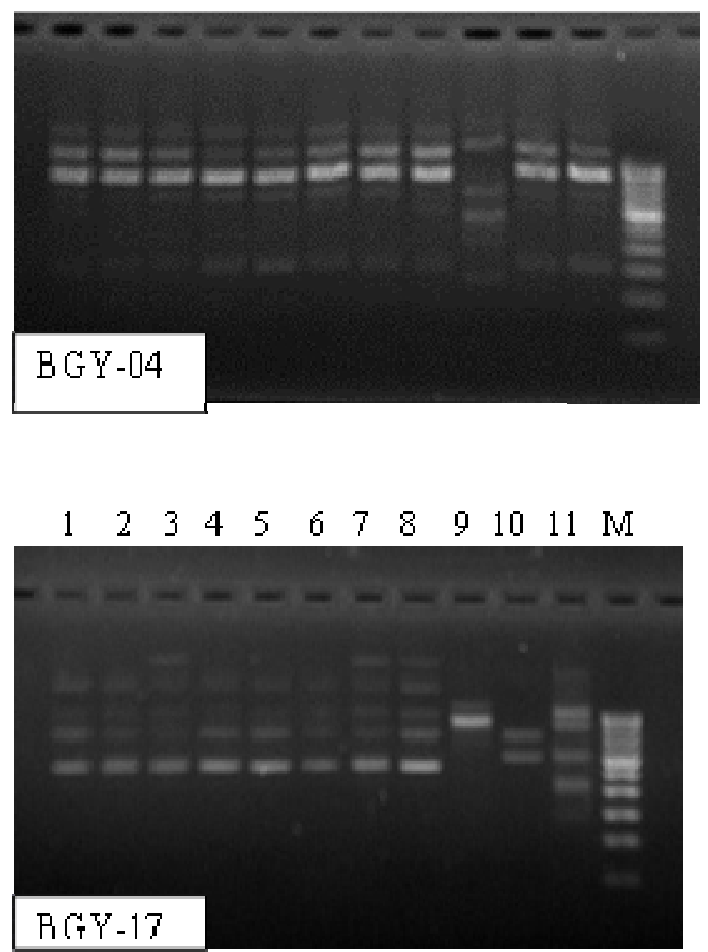

Figure 2. RAPD profile of muga silkworm $A$. assamensis accessions obtained with primers BGA-02, BGA-16, BGL-06, BGY-04, BGY-16, BGY-17. Serial number of the accessions is as given in the Table $3 . M=S t a n d a r d$ DNA marker, 100 bp DNA ladder.

High molecular weight DNA was extracted from the silk glands of the $A$. assamensis silkworms. The $\lambda_{260} / \lambda_{280}$ ratio was greater than 1.8 and the $\lambda_{260} / \lambda_{230}$ ratio was greater than 2.0, indicating the purity of extracted DNA (Sambrook et al., 1989; Henry, 1997). DNA yield ranged from 244$548 \mu \mathrm{g} / \mathrm{g}$ of silk gland tissue.

A total of 150 RAPD primers were screened; out of which 36 yielded good amplification and hence were chosen for fingerprinting the 11 muga silkworm accessions. Poorly stained, unique, and very low-frequency bands from the data set were discarded for further analysis.
Among the 150 primers tested, 36 selected primers generated 309 bands, of which 296 were polymorphic. RAPD profile generated with primers BGA-02, BGA-16, BGL-06, BGY-04, BGY-16 and BGY-17 are depicted in Figure 2. The level of polymorphism revealed by this study was high. But the selected accessions were similar at morphological level. The total number of DNA fragments amplified and the number of polymorphic bands from each accessions with individual primers are shown in Table 2. All the 11 accessions were quite distinct in their RAPD profiles. Percentage of polymorphism 
Table 2. Banding profile produced by selected RAPD primers.

\begin{tabular}{|c|c|c|c|c|c|c|}
\hline $\mathbf{S} / \mathbf{N}$ & Primer & $\begin{array}{c}\text { Nucleotide sequence } \\
\left(5^{\prime} \rightarrow 3^{\prime}\right)\end{array}$ & $\begin{array}{c}\text { Total } \\
\text { bands }\end{array}$ & $\begin{array}{l}\text { Polymorphic } \\
\text { bands }\end{array}$ & PPB & $\begin{array}{l}\text { Range of fragment } \\
\text { size (bp) }\end{array}$ \\
\hline 1 & BGA-01 & CAGGCCCTTC & 6 & 6 & 100 & $350->1000$ \\
\hline 2 & BGA-02 & TGCCGAGCTG & 10 & 10 & 100 & $450->1000$ \\
\hline 3 & BGA-05 & AGGGGTCTTG & 9 & 9 & 100 & $150->1000$ \\
\hline 4 & BGA-16 & AGGTGACCGT & 9 & 8 & 88.9 & $400->1000$ \\
\hline 5 & $B G C-12$ & TGTCATCCCC & 11 & 11 & 100 & $250->1000$ \\
\hline 6 & BGD-19 & GGGGTGACGA & 7 & 7 & 100 & $400->1000$ \\
\hline 7 & BGK-01 & CATTCGAGCC & 9 & 9 & 100 & $400->1000$ \\
\hline 8 & BGK-19 & CACAGGCGGA & 8 & 8 & 100 & $300->1000$ \\
\hline 9 & BGL-02 & TGGGCGTCAA & 12 & 12 & 100 & $200->1000$ \\
\hline 10 & BGL-06 & CAGGGAAGAG & 9 & 9 & 100 & $200->1000$ \\
\hline 11 & BGL-17 & AGCCTGAGCC & 17 & 17 & 100 & $400->1000$ \\
\hline 12 & BGM- 20 & AGGTCTTGGG & 8 & 8 & 100 & $300->1000$ \\
\hline 13 & BGN-03 & CTGTTGCTAC & 9 & 9 & 100 & $300->1000$ \\
\hline 14 & BGN-04 & GACCGACCCA & 12 & 11 & 91.7 & $300->1000$ \\
\hline 15 & BGN-05 & ACTGAACGCC & 9 & 9 & 100 & $150->1000$ \\
\hline 16 & BGN-16 & AAGCGACCTG & 10 & 10 & 100 & $250->1000$ \\
\hline 17 & BGW-01 & CTCAGTGTCC & 8 & 7 & 87.5 & $400->1000$ \\
\hline 18 & BGW-02 & ACCCCGCCAA & 13 & 12 & 92.3 & $250->1000$ \\
\hline 19 & BGW-03 & GTCCGGAGTG & 10 & 10 & 100 & $150->1000$ \\
\hline 20 & BGW-04 & CAGAAGCGGA & 7 & 7 & 100 & $450->1000$ \\
\hline 21 & BGX-06 & ACGCCAGAGG & 9 & 9 & 100 & $175->1000$ \\
\hline 22 & BGY-02 & CATCGCCGCA & 5 & 5 & 100 & $350-900$ \\
\hline 23 & BGY-03 & ACAGCCTGCT & 5 & 4 & 80 & $350-1000$ \\
\hline 24 & BGY-04 & GGCTGCAATG & 8 & 6 & 75 & $375->1000$ \\
\hline 25 & BGY-05 & GGCTGCGACA & 7 & 4 & 57.1 & $275->1000$ \\
\hline 26 & BGY-06 & AAGGCTCACC & 10 & 9 & 90 & $350->1000$ \\
\hline 27 & BGY-07 & AGAGCCGTCA & 4 & 4 & 100 & $280->1000$ \\
\hline 28 & BGY-08 & AGGCAGAGCA & 9 & 8 & 88.9 & $300->1000$ \\
\hline 29 & BGY-09 & AGCAGCGCAC & 7 & 5 & 71.4 & $250->1000$ \\
\hline 30 & $B G Y-10$ & CAAACGTGGG & 4 & 4 & 100 & $200-900$ \\
\hline 31 & $B G Y-11$ & AGACGATGGG & 5 & 4 & 80 & $250->1000$ \\
\hline 32 & BGY-13 & GGGTCTCGGT & 7 & 7 & 100 & $300-800$ \\
\hline 33 & BGY-14 & GGTCGATCTG & 6 & 6 & 100 & $250-1000$ \\
\hline 34 & $B G Y-16$ & GGGCCAATGT & 8 & 7 & 87.5 & $200->1000$ \\
\hline 35 & $B G Y-17$ & GACGTGGTGA & 10 & 10 & 100 & $400->1000$ \\
\hline 36 & BGY-18 & GTGGAGTCAG & 12 & 12 & 100 & $200->1000$ \\
\hline Total & & & 309 & 293 & & \\
\hline Average & & & 9 & & 94.82 & \\
\hline
\end{tabular}

$\mathrm{PPB}=$ Proportion of polymorphic bands.

detected with each primer was as high as $100 \%$ in 24 primers (BGA-01, 02, 05, BGC-12, BGD-19, BGK-01, 19, BGL-02, 06, 17, BGM-20, BGN-03, 05, 16, BGW-03, 04, BGX-06, BGY-02, 07, 10, 13, 14, 17, 18) to $57.14 \%$ detected by BGY-05. The number of bands per primer ranged from 4 (BGY-07 and BGY-10) to 13 (BGW-02) with an average of 8.58 scorable bands per primer. Cluster analysis (UPGMA) was generated by computing polymorphic as well as monomorphic markers to con- struct the dendogram. Jaccard's similarity coefficients ranged from 0.122 to 0.863 (Table 3). Maximum similarity was noticed between $\mathrm{Aa} 02$ and $\mathrm{Aa} 03$ strains and the minimum similarity was observed between $\mathrm{Aa} 04$ and $\mathrm{Aa}$ 09. Associations among the 11 accessions revealed by UPGMA cluster analysis based on RAPD profile are presented in Figure 3. All the accessions could be split into two major clusters, at $50 \%$ similarity level, with Aa 09 on one cluster and the remaining strains on the other 
Table 3. Similarity matrix for Jaccard's coefficient based on RAPD banding pattern for $11 \mathrm{~A}$. assamensis accessions.

\begin{tabular}{|l|c|c|c|c|c|c|c|c|c|c|c|}
\hline Accessions & S1 & S2 & S3 & S4 & S5 & S6 & S7 & S8 & S9 & S10 & S11 \\
\hline S1 & & 0.838 & 0.832 & 0.654 & 0.807 & 0.813 & 0.816 & 0.792 & 0.130 & 0.538 & 0.538 \\
S2 & & & 0.863 & 0.667 & 0.799 & 0.842 & 0.784 & 0.728 & 0.127 & 0.500 & 0.546 \\
S3 & & & & 0.707 & 0.781 & 0.837 & 0.827 & 0.779 & 0.137 & 0.528 & 0.568 \\
S4 & & & & & 0.667 & 0.673 & 0.667 & 0.616 & 0.122 & 0.475 & 0.475 \\
S5 & & & & & & 0.860 & 0.736 & 0.705 & 0.141 & 0.550 & 0.535 \\
S6 & & & & & & 0.809 & 0.753 & 0.150 & 0.547 & 0.555 \\
S7 & & & & & & & 0.846 & 0.138 & 0.559 & 0.575 \\
S8 & & & & & & & & & 0.129 & 0.607 & 0.591 \\
S9 & & & & & & & & & & 0.159 & 0.163 \\
S10 & & & & & & & & & & & 0.710 \\
S11 & & & & & & & & & & & \\
\hline
\end{tabular}

Rescaled Distance cluster Combine
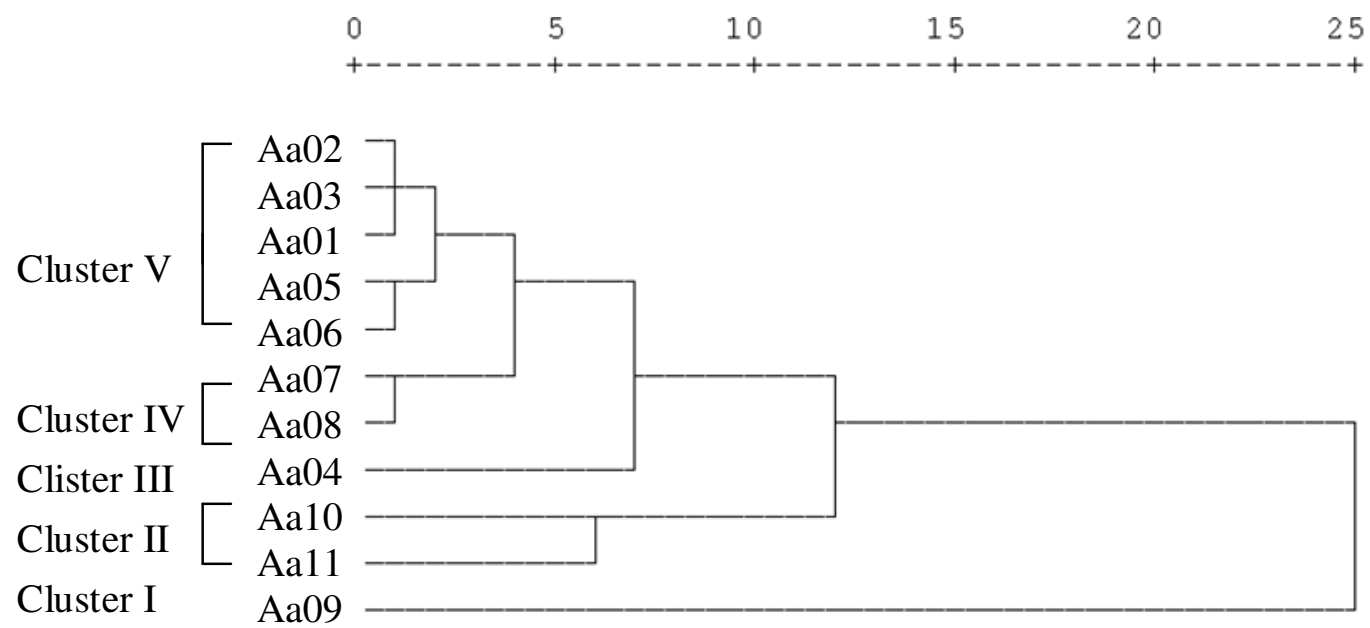

Figure 3. Dendrogram illustrating genetic relationships among the eleven $A$. assamensis accessions.

cluster. At $60 \%$ similarity level, accessions Aa 10 and $\mathrm{Aa}$ 11 combine to form another cluster II, and accessions $\mathrm{Aa}$ 02, Aa 03, Aa 01, Aa 05, Aa 06, Aa 07, Aa 08 and Aa 04 combined to form cluster III, making three clusters along with cluster I. At $80 \%$ similarity level all the accessions were divided into 5 major clusters. The accessions Aa 09, $\mathrm{Aa} 11$ and $\mathrm{Aa}$ 10, $\mathrm{Aa}$ 04, Aa 08 and $\mathrm{Aa} 07$ made four clusters: cluster I, cluster II, cluster III and cluster IV, respectively and the remaining accessions $\mathrm{Aa} \mathrm{02,Aa} \mathrm{03,}$ $\mathrm{Aa} 01, \mathrm{Aa} 05$ and Aa 06 made the cluster V. Cluster V of $80 \%$ similarity level, sub groups into 2 clusters at higher similarity levels: three domesticated accessions (Aa 01, Aa 02 and $\mathrm{Aa}$ 03) collected from Assam (Mangaldoi and Jorhat) and Meghalaya (Tura) combined to form one cluster and the other cluster comprised of two wild accessions ( $\mathrm{Aa} 05$ and $\mathrm{Aa}$ 06).

Since RAPDs are random selection of DNA sequence, it was apparent in the study that RAPD technique was sensitive enough to detect differences between accessions of muga silkworm in which differentiation is not always possible morphologically. In the present study, $94.82 \%$ polymorphism demonstrated the potentiality of the method in evaluating genetic diversity within the germplasm. Wide range of similarity $(0.122$ to 0.863$)$ indicated high genetic diversity in muga silkworm germplasm. Cluster analysis of RAPD data using UPGMA revealed that three high-yielding strains $\mathrm{Aa}$ 09, Aa 10 and $\mathrm{Aa} 11$ were genetically distinct from the remaining accessions. In the dendogram it was interesting to find that at higher similarity levels, there was clear demarcation between the wild and domesticated muga silkworm accessions. The domesticated accessions Aa 02, Aa 03 and $\mathrm{Aa} 01$ making one cluster, the other domesticated one $\mathrm{Aa} 09$ making the other cluster and the wild accessions were grouped in five different clusters. For sustenance of the silk industry such studies are very important and their utilization in silkworm breeding is inevitable for the development of region specific races. Such studies are 
very much necessary to develop a farmer preferred variety which will thrive very well at the prevailing local conditions of Indian villages particularly NER of India. Morphologically, all the strains are green in larval colour except the accession Aa 08 which is blue in colour but it did not show any marked genetic divergence from other accessions. It was also found that the progenies of $\mathrm{Aa} 08$ are not always blue in colour favouring the Mendel's law of segregation. Morphologically similar individuals were also genetically dissimilar and grouped into different clusters.

Modern tools like molecular markers offer a wide range of applications in silk breeding programs. India being a country with diverse environmental conditions, the local races are rich reservoirs of many resistant genes, and molecular markers are inevitable tools to study inheritance of such complex traits. The amplification products resulting from the RAPD assay vary between strains and hence can be used as genetic markers as well as to construct linkage maps. Considering the diversity, the genotypes belonging to different groups will constitute promising parents for hybridization in silk improvement program. Thus, the above study along with the analysis of their rearing performance was essential to understand the genetic relationship among the muga silkworm genotypes for use in muga silkworm breeding program.

\section{ACKNOWLEDGEMENTS}

The authors are thankful to the Director, NEIST, Jorhat, Assam, India, for encouragement and for providing laboratory facilities for the work. The authors are also thankful to the Director, CMER\&TI, Jorhat, Assam, India, for encouragement and permission to utilize the silkworm accessions for the study.

\section{REFERENCES}

Adiguzel A, Gulerag A, Baris O, Gulluce M, Sahin F, Sangul M (2006). RAPD and FAME analysis of Astragalus species growing in eastern Anatolia region of Turkey. Biochem. Syst. Ecol. 34: 424-432.

Ashwath SK (2000). Strategies in genetics and molecular biology for strengthening silkworm breeding. Indian J. Seric. 32: 69-86.

Awasthi AK, Kar PK, Srivastava PP, Rawat N, Vijayan K, Pradeep AR, Urs SR (2008). Molecular evaluation of bivoltine, polyvoltine and mutant silkworm (Bombyx mori L.) with RAPD, ISSR and RFLP-STS markers. Indian J. Biotechnol. 7: 188-194.

Chakravorty R, Barah A, Neog K, Rahman SAS, Ghose J (2005). Package of practices for muga culture, In: Package of practices of Muga, Eri and Mulberry Sericulture for North Eastern Region of India, Central Muga Eri Research \& Training Institute, Central Silk Board, Lahdoigarh, Jorhat, pp. 1-23.

Chakravorty R, Barah A, Neog K, Das K, Kakati PK (2006). Variability in muga silkworm Antheraea assamensis Helfer. Indian Silk, Nov.16-17.

Choudhury SN (2005). Genetics-Muga worm. In: Biology of silkworms and host plants. p. 60.

Datta RK (1984). Improvement of silkworm races in India. Sericologia. 24: 393-415.
Goldsmith MR (1995). Genetics of the silkworm. In: Goldsmith MR, Wilkins AS (eds) Molecular Model Systems in the Lepidoptera. Cambridge University Press, London. pp. 21-76.

Henry RJ (1997). Practical Applications of Plant Molecular Biology, $1^{\text {st }}$ ed, Chapman and Hall, London.

Hug LA, Roger AJ (2007). The impact of fossils and taxons sampling on ancient molecular dating analysis. Mol. Biol. Evol. 24(8): 1889-1897.

Krumm JT, Hunt TE, Skoda SR, Hein GL, Lee DJ, Clark PL., Foster JE (2008). Genetic variability of the European corn borer, Ostrinia nubilalis, suggests gene flow between populations in the Midwestern United States. J. Insect. Sci. 8: p. 72, available online: insectscience.org/

Meimberg H, Thalhammer S, Brachmann A, Heubl G (2006) Comparative analysis of a translocated copy of the trnk intron carnivorous family Nepenthaceae. Mol. Phylogenet. Evol. 39: 478490.

Murthy BCK, Prakash BM, Puttaraju HP (2006). Fingerprinting of nondispausing silkworm, Bombyx mori, using random arbitrary primers. Cytologia, 71(4): 331-335.

Nagaraja J (2002). Application of genetic principles for improving silk production. Curr. Sci. 83: 409-414.

Nagaraja GM, Nagaraju J (1995). Genome fingerprinting of the silkworm Bombyx mori by random arbitrary primers. Electrophoresis, 16: 16331638.

Neog K, Chakravorty R, Deka GM, Zamal T (2008). Morphological characterization and rearing performance of Muga silkworm Antheraea assamensis Helfer germplasm accessions. Sericologia, 48(3): 301-310.

Pornkulwat S, Skoda SR, Thomas GD, Foster JE (1998). Random Amplified Polymorphic DNA used to identify genetic variation in ecotypes of the European corn borer (Lepidoptera: Pyralidae). Ann. Entomol. Soc. Am. 95: 719-725.

Promboon A, Shimada T, Fujiwara H, Kobayashi M (1995). Linkage map of random amplified polymorphic DNAs (RAPDs) in the silkworm, Bombyx mori. Gen. Res. 66: 1-7.

Rath P, Rajeseger G, Cheng JG, Kumar PP (1998). Phylogenetic analysis of Dipterocarpus using random amplified polymorphic DNA markers. Ann. Bot. 82: 61-65.

Reineke A, Kartlovsky P, Zebitz CPW (1999). Amplified fragment length polymorphism analysis of different geographic populations of gypsy moth, Lymantria dispar (Lepidoptera: Lymantriidae) Bull. Entomol. Res. 89: 79-88.

Ribeiro LFC, Zanatta DB, Bravo JP, Brancalhao RMC, Fernandez MA (2009). Gen. Mol. Res. 8(1): 144-153.

Sambrook J, Fritsch EF, Maniatis T (1989). Molecular Cloning: A Laboratory Manual, 2nd ed, Nolan C (ed), Cold Spring Harbor Laboratory Press, Cold Spring Harbor, New York.

Singh L (1997). Assessment of genetic diversity by DNA profiling and its significance in silkworm Bombyx mori L. Electrophoresis 18: 16761681.

Sokal RR, Sneath PHA (eds.) (1963). Principles of numerical taxonomy. W.H. Freeman, San Fransisco.

Sun Y, Xia N, Stapleton CMA (2005). Relationship between Bambusa species (Poaceae, Bambusoidae) revealed by random amplified polymorphic DNA. Biochem. Syst. Ecol. 34: 417-423.

Suzuki Y, Gage L, Brown DD (1972). The genes for silk fibroin in Bombyx mori. J. Mol. Biol. 70: 637-649.

Thanananta N, Saksoong P, Peyachoknagul (1997). RAPD technique in silkworm (Bombyx mori): Strain differentiation and identification. Thammasat. Int. J. Sci. Technol. 2(2): 47-51.

Vijaya K, Anuradha HJ, Nair CV, Pradeep AR, Awasthi AK, Saratchandra B, Rahman SAS, Singh KC, Chakraborti R, Urs SR (2006). Genetic diversity and differentiation among populations of the Indian eri silkworm, Samia cynthia ricini, revealed by ISSR markers. J. Insect Sci. 6: 30.

Williams JGK, Kubelik AR, Livak KJ, Rafalski JA, Tingey SV (1990). DNA polymorphism amplified by arbitrary primers are useful genetic markers. Nucl. Acids Res. 18: 6531-6535. 